\title{
Prioritizing the Effective Factors to Customer's Satisfaction
}

\author{
Dr Mohsen Nazari (Corresponding author) \\ Department of Management, Tehran University \\ P.O.Box 14155-6311, Jalal-Al-Ahmad Highway, Pol-e-Nasr, Tehran, Iran \\ E-mail: Mohsen.nazari@ut.ac.ir \\ Mohammadreza Qaemi Divkolaei \\ Nor-e Toba University \\ Tehran, Iran \\ E-mail: mrgd_1359@yahoo.com \\ Majid Bagheri Sorkhi \\ Industrial Management, Mazandaran Cement Co. \\ Tehran, Iran
}

Received: September 8, 2011

Accepted: October 19, 2011

Published: January 16, 2012

doi:10.5539/ijbm.v7n2p236

URL: http://dx.doi.org/10.5539/ijbm.v7n2p236

\begin{abstract}
According to the innovative managerial trends, since the customers are the only source of return on investment (ROI), customer satisfaction is a suitable standard of performance in every business. In the new revolutionary world, keeping the customer and maintaining the loyalty need a great effort. A majority of business organizations miss their customers simply because they ignore the innovative methods of customer relationship. A loyal customer should be seen as a prosperous and valuable sale source who can help the organization make better future plans. So it is necessary to do research to recognize the structure of customer satisfaction and determine its effective factors.

In this paper due to the importance of above mentioned points, after analyzing the gathered information from the customers of Mazandaran Cement Co. and stating the achieved results and suggestions, it turned became apparent that factors including response to questions and demands of customers, brand and price seem to be effective factors in customer satisfaction.
\end{abstract}

Keywords: Customer, Satisfaction, Loyalty, Customer expectations

\section{Introduction}

Customer satisfaction has certainly been one of the main strategic considerations of different businesses in the last few decades. Nowadays customers are the most essential part for the existence of every firm in the world of business and it seems quite obvious that firms can be no longer indifferent to their customers' expectations and demands. Companies must direct all their activities and powers towards the customer satisfaction, because the customers are the only source for return on investment (ROI). Although firms lose yearly round 10 to 30 per cent of their customers, they often do not consider who they lose, when they lose and why they lose them. Many firms traditionally emphasize attracting new customers without worrying about the customers they have already lost. These firms can be likened to a perforated bowl which loses its water. Also managers in these firms, instead of stopping the leakage, are in search of new resources to attract new customers (Hill, 2006).

In innovative managerial trends, customer satisfaction is considered as the standard for performance and progress in every trading system. Furthermore, measuring customer satisfaction encourages all staff in a system to contribute to achieving customer satisfaction. Thus, measuring customer satisfaction leads to an increase in the efficiency of the organization. To achieve a customer-based approach, some organizations consider customer satisfaction as a criterion and, after measuring it quantitatively, utilize it in their decisions as well as their analyses (Baradaran Kazemzadeh, 2005). 
A reassured and heartened customer will never have a clear reason to change his suppliers. As this relation lengthens, a sense of assurance and relief is built up. Therefore, in all long-term trading relations, confidence exists permanently (Makizadeh, 2009).

Perhaps one of the reasons why organizations neglect customer satisfaction is that it is difficult to correlate this important factor with profitability. Another reason might be the difficultly to convert the data about the customer satisfaction to executive measures. These types of data mostly have inter-organizational sources (expressed by the employees) and fail to obviously show what customers deem important and what the basis of the conceptions is (Maghsoudi, 2003).

Information about customer satisfaction can result in constructive operational plans, and also can improve the resource planning decisions. Moreover, it can make the quality of processes and products more efficient. Sustaining the competitive advantage and the lifetime profitability can be largely related with the integration of customer satisfaction as well as business strategies and operations. Finally, a manager should make use of this information to analyze the areas that, when improved, can have a noticeable impact. When there is no guarantee for the satisfied customers to return, it goes without saying that unsatisfied customers will never come back. An analysis on the effective variables on customer satisfaction must make some suggestions for managers to increase the total probability a customer return (Makizadeh, 2009).

Since customers' ideas can directly guide the organization towards an efficient performance, establishing a feedback mechanism is absolutely essential. This way, the positive and effective features as well as the negative and debilitative points will be identified. Considering the saturation of the indoor cement market in recent years and the necessity to enter the markets in the neighboring countries, it is required to take the features of working in a competitive market into consideration. Right now, it is necessary to have a planned and systematic approach in customer relationship management.

Thus, the main purpose to do this research was to help superior management of Mazandaran Cement Co. establish plans in order to improve customer satisfaction and raise the quality of the products by identifying and prioritizing the influential variables on customer satisfaction. It is quite obvious that the research findings can be a reliable basis to make strategic decisions regarding the customers and ultimately regarding the main business strategies. The secondary purpose of this research is to anticipate the amount of customers' interest in factors that can influence the decisions about the future operation of the company (For example, the availability of ordering from internet). Another secondary purpose is to get aware of the customer's evaluation about the latest affairs of the organization and also to recognize the strong and the weak points. Later on after proposing the theoretical basis of the topic and introducing the utilized method, the results of the study will be explained and suggestions will be made to develop the marketing and sales activities.

\section{Satisfaction}

Customer satisfaction is one of the basic issues in the concept of evaluation which is pursued in many businesses. Customer satisfaction is usually evaluated periodically or after each structural change. By reviewing the literature on customer satisfaction we perceive that the descriptions are usually analyzed and examined by collecting customers' ideas.

Reviewing the researchers' ideas about the definitions of satisfaction, we will see that some main factors exist in all definitions. A set of these factors can result a comprehensive definition about satisfaction. The result of these factors can be summarized as: Customer satisfaction is an emotional reaction or a state of mutual cognitive understanding (Kate \& Reynolds, 2009).

Jamal and Naser define Customer satisfaction as a customer's feeling or attitude toward a product or service after using it. These two researchers state that Customer satisfaction is the main result of a marketer's performance that acts as a link among the various stages of purchasing behavior of a consumer. For example, if customers are satisfied with a specific service, they are most likely to repeat their purchases (Jamal, 2002).

Blanchard and Galovi believe "Customer satisfaction occurs as a result of customer perception during a trade and the relationship is valued so that the price equals the proportion of the quality of a given service with the customer prices and casts".

The articles about the relation between customers satisfaction, customers taste and profitability show that customer satisfaction affects on customer taste and consequently on profitability. Supporters of this theory are researchers such as Anderson and Fornell (1994), Thompson (1993), Skelet et al (1995), Schindler and Bawn(1995), Storbaka et al (1994). Zitamel et al (1990). These researchers explain the relation between satisfaction, taste and profitability. The statistic analysis resulting from the relation was identified by Nelson et al (1992) who examined the relation between customer satisfaction and profitability in hospitals. Rost and 
Zahoorick (1991) examined the relation between customer taste and keeping customers in a retail banking system (Hallowell, 1996).

\subsection{Changes in effective factors on customer satisfaction in current situation}

In today's world, we should talk about perfect markets which maintain different features from the past. One of the main features to point out is the power and skill of customers and a decrease in influence of the advertisement. Today suppliers of industrial and consumptive goods are encountered with customers who have unlimited demands. However they are less affected by the impact of traditional marketing. On the other hand, goods in a market is not considerably different so that when a customer's desired trade mark mark is not available, a new brand is easily replaced. This shows a lack of customers' loyality. Price competition has also lost its former meaning and market-oriented and customer-based organizations think of sustaining and promoting customers' loyalty as a new means instead of competing over a price (Chistopher, 1996).

In recent years, the development of electronic business as a promise for economic advancement has attracted a lot attention. Many organizations, either from private sector or from public sector, have invested a great amount of money on electronic business in order to achieve a remarkable success. The size of electronic business market is highly increasing. Supporting customers and winning their satisfaction is one of the priorities in today's modern companies. The researches show that using the internet in business activities is an easy way to gain precise information about customer demands and their preferences (Mosavi \& Nonezhad, 2009).

\subsection{Executive and conceptual design of the research}

When the statistical data are collected, a questionnaire is used to ask customers about their habits, experiences, preferences and believes. In most writings, it is emphasized that the delivered service or product should be identified by customers. It may be achieved by group or individual interview or by asking customers. Also in some researches the basic information is provided by sampling a special group of customers. Some researchers turned to group interviews with customers and some others interviewed the experts in that given industry. Since deploying a simple economical evaluation on customer satisfaction can make it possible to correlate analysis between desired demands, every tool along with a set of information can be utilized to explain a picture of a product or service. The combination of the tools may be useful to give a comprehensive picture. The first decision must be aimed at what we want to know and what we want to do. Right after identifying the purposes, we should make a decision about the most efficient way for data collection.

The first step is to formulate what we are going to know about the customers. After taking the first step, choosing the right way to collect data will facilitate the research. The most important decision that must be made about the evaluation framework is how to adjust the process of providing satisfaction with properties of products or services and identify the properties of the system involved in this process. The second decision is about the means of doing the job and the way to convert the features to means of measurement. Then we are able to utilize them in data collection and data analysis.

Translating the features of system to means of data collection is a crucial step. In researches on customer satisfaction measuring the quality and the performance, when the concepts were one-dimensional, were observed as individual features with one question for an evaluation. Also when the features were multidimensional, measuring the quality and performance were used as compound features from the total received points from each set of questions. Some researches discussed the need of identifying partial importance of the operational features of a given product. That is because they have different levels in customers' view point [for example Kano model]. Thus it is necessary to evaluate the features according to their weight. This allows us to evaluate customer satisfaction better and, while analyzing data, make the necessary modification according to the weight of each feature (Plepsy, 2003).

To sum up, it should be stated that identifying the effective factors on customer performance which is based on the way of customer decision making, can be a starting point to recognize customer incentives in order to make purchasing decisions (Divandarri, 2005).

Considering what we mentioned above, a primary questionnaire was provided, and after holding several meeting with the managers and experts of marketing in the company as well as some customers, the questionnaire was revised and took its final form. This questionnaire was used in order to analyze the data quantitatively and also to collect and use the customers' viewpoints and attitudes in Mazandaran Cement company. It should be mentioned that a part was added to the final section of the questionnaire as the weak and strong points of the organization and also another part was added for free comments. The purpose to add the comment part was to achieve qualitative information from the customers' ideas on the current performance of the sale section. Table 1 contains the final list of the influential factors on customer satisfaction. 


\section{Methodology}

This research is methodologically a descriptive and scale type and since it is oriented towards applied knowledge, the purpose of this research is investigative.

A general theme of the stages of the activity can be seen in figure 1.

\subsection{Population and statistical sampling}

The populations of the study include sale agents, construction companies and producers of the cement products who regularly purchase from Mazandaran Cement company.

The mass of the needed sample was calculated by the following formula:

$$
n=\frac{N Z_{\frac{\alpha}{2}}^{2} P(1-P)}{\mathrm{E}^{2}(N-1)+Z_{\frac{\alpha}{2}}^{2} p(1-p)}
$$

In which the total number of the population was around 300 cases, reliability level $95 \%$ and the estimated error was 0.07 . $\left(\mathrm{Z}_{\alpha / 2}=1.96, \mathrm{P}=0.5\right)$.

According to the calculation, the number of the samples was calculated 103. It should be mentioned that 112 sample were used in the analysis. The customers were randomly selected from Neka, Behshahr, Babol, Qaemshahr and Sari.

\subsection{Data collection}

In this research, library study was vastly used which includes review of the related and researches, article study, Latin and Persian books study and also internet to access the recent findings. After gathering the material, a primary questionnaire was designed which took its final form following several meetings with managers and sale experts of the company as well as some customers. The questionnaire included 40 items. In addition, to measure the attitudes Likert scale was utilized. (1 for "unimportant" and 5 for "necessary"). Also a questionnaire was use in order to analyze the data quantitatively and also to collect and use customers' viewpoints and the attitudes in Mazandaran Cement company.

\subsection{Reliability and validity}

After analyzing and studying the questionnaire and comparing with former studies measure, the validity of the questionnaire was done by consulting managers and sale experts as well as some customers.

To measure the reliability of the questionnaire, an introductory sample was used (15 customers were selected randomly). After gathering the questionnaire, Cronbach's alpha was used to test the reliability of the questionnaire. According to the results, the reliability of the means of data collection is $82 \%$ and we can say that it has a good reliability.

\subsection{Data analysis method}

To analyze the collected data from the questionnaire, Freidman test was utilized in Spss16 software. As mentioned earlier, some of the features used in the questionnaire are related to the factors that can be considered as the future plans of the company to carry on the strategies in sale and marketing sectors. Finally the average of the obtained numbers by the features are considerate as a basis for the amount of customers' interest in the fields and is mentioned as one of the results of the research at the end.

Thus by doing this research we can recognize both the amount of customer partial satisfaction from the current affairs of the organization and the strong and weak points of it. We may also make an appropriate prediction about the possible scenario in managing the communication with customers.

\section{Data analysis}

\subsection{The features of statistical society}

As mentioned before, to collect data, 112 customers of the Mazandaran Cement Company were selected. Among the customers, 20 of them had guidance school degree, 43 of them had a diploma; 26 of them had an associated degree; 20 of them had a bachelor degree and 3 people had a master degree. Also 16 people use type 1 cement, 96 people use type 2, 3 people use Pozolani and 33 people use PKZ cement. Table 2 contains information about distribution purchasing duration and the amount of consumption in statistical population.

\subsection{Results of Freidman variance analysis}

Freidman test, which is a non-parametrical equal variance, was used to compare the average of the ranks among some groups. 
Hypothesis $\mathrm{H}_{0}$ : The 10 effective factors on customer satisfaction have equal significance.

Hypothesis $\mathrm{H}_{1}$ : At least one pair of the factors does not have equal significance.

After doing the test, it became clear that since the significance level $(0.000)$ is less than the errors $(0.05)$, as a result in 95 percent reliability it can be stated that the $\mathrm{H}_{0}$ hypothesis about equality of the ten effective factors on customers' satisfaction is rejected and $\mathrm{H}_{1}$ hypothesis about inequality of the rank of the average is accepted. In table 3 the priority of the factors are arranged based on Freidman test.

\subsection{Analysis customers' ideas about future properties}

As we noted in the first part, one of the main purposes of this research was to gain information about the as issues that can potentially play an important role in future strategies of the organization on marketing and sale Table 5 contain ranking of the features that are related to this issue. This ranking is based on the average of the gained scores.

\section{Conclusion}

In this research the effective factors on customers' satisfaction of Mazandaran Cement Company was examined and identified, then prioritize based on customers' opinions. It should be mentioned that according to the previous researches, no similar research was done in Iran. Therefore, since the research was done in a manufacturing company (all the observed materials were done in service organizations focusing on customers' interest), it is considered as a new research.

According to the results, which were shown in tables 3 and 4, it became apparent that despite the high price of the company's product in proportion to the price of the competitors' products, customers are more sensitive to some other factors. The factors include: the way of responding to customers' questions, high quality of the product, quality of packaging, attempt to protect the environment and convenience in ordering and payment.

\subsection{Suggestions}

Based on the factors mentioned in this company some suggestions were made which seem usable, including:

- $\quad$ Upgrading order registration system with new technologies to facilitate the job

- Automation delivery system and informing about the time of package delivery by a call or a short massage.

- Improving the potentiality of cement delivery inform of a package.

- Making cement delivery in packages less than $50 \mathrm{~kg}$ possible (like chalk which is distributed in $40 \mathrm{~kg}$ bags).

- $\quad$ Trying to inform adequately and timely about the usages and the differences of the products varieties.

- $\quad$ Using more resistible packages with less leakage and distinguished color for each kind of product.

- Allocating special welfare for loyal customers (considering that customers are the most efficient means of advertizing the products of the company).

- Trying hard to keep the position of the company brand as a product with a high quality and locally manufactured (considering that most customers consider these two features as the biggest reason to purchase from this company).

\section{Recommendations for Future Research}

-Analyzing customer satisfaction quantitatively (based on the factors mentioned in this study)

-Searching and finding out methods to increase customer satisfaction.

-Analyzing effective factors in customer satisfaction at the national level.

- Identifying the components of customer satisfaction in rival companies.

\section{References}

Baradaran Kazemzadeh, R. (2005). Mass parameters to increase of customer satisfaction. Bimonthly officiall publication of Shahed university, 71-78.

Chistopher, M. (1996). From brands Values to customer value. Journal of marketing practice, 55-66. http://dx.doi.org/10.1108/EUM0000000000007

Divandarri, A. a. (2005). Compiling \& designing a model of evaluate the customer satisfaction in banking industry and mesurment of Mellat bank customers satisfaction according to mentioned model. Business researches quarterly, 185-223.

Hallowell, R. (1996). The relationships of customer satisfaction, customer loyalty \& profitability: An empirical 
study. International journal of service industry Management, 27-42. http://dx.doi.org/10.1108/09564239610129931

Hill, N. (2006). Customer Satisfaction Measurent. Tehran: Rasa Publication.

Jamal, A. (2002). Customer satisfaction and retail banking: An assessment of some of the key antecedents of Customer satisfaction in retail banking. European journal of marketing, 146-160. http://dx.doi.org/10.1108/02652320210432936

Kate, L., \& Reynolds, C. L. (2009). Dysfunctional customer behavior severity: An empirical examination. Journal of retailing, 321-335. http://dx.doi.org/10.1016/j.jretai.2009.05.005

Maghsoudi, M. (2003). The relationship of customer satisfaction, efficiency and effectiveness of process. Fourth international conference of quality managers. Tehran.

Makizadeh, A. H. (2009). Examine the communicate with service quality and customers loyalty in commercial and services organization. Management vision, 29-47.

Mosavi, S., \& Nonezhad, S. a. (2009). Examine the factors of influential in customer satisfaction (New model). Management quarterly, 56-69.

Plepsy, M. O. (2003). Customer satisfaction: The review of literature and application to product-service system. International institute for industrial invironmental economics.

Table 1. List of influential factors on customers' satisfaction

\begin{tabular}{|l|l|}
\hline No & Factors \\
\hline 1 & Cement delivery \\
\hline 2 & Variety of products \\
\hline 3 & Quality of organization's response to customer's question \\
\hline 4 & Price \\
\hline 5 & Offering appropriate information with the product \\
\hline 6 & Positive image of the organization's brand \\
\hline 7 & Convenience in ordering \\
\hline 8 & Packaging \\
\hline 9 & Quality of the product \\
\hline 10 & Offering incentive to encourage to keep purchasing \\
\hline
\end{tabular}

Table 2. Distribution of duration and amount of customers' purchase

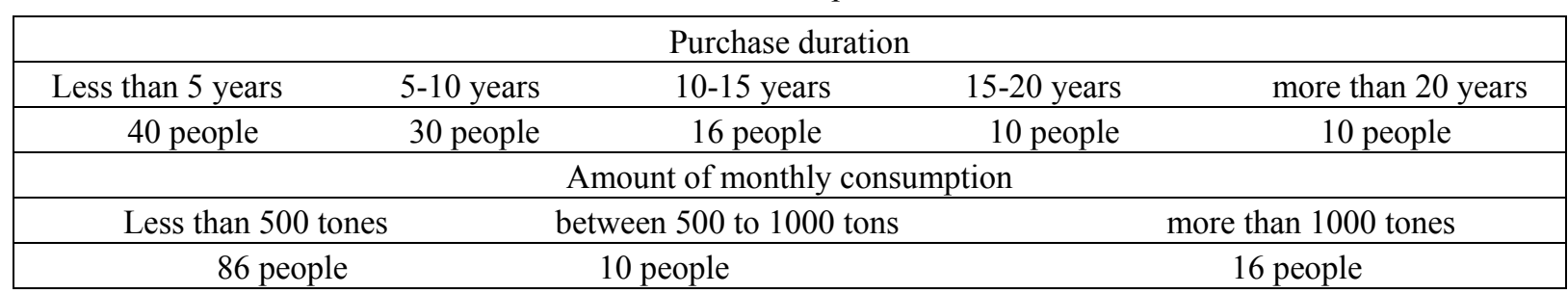

Table 3. Priorities of the effective factors on customers' satisfaction

\begin{tabular}{|c|c|c|c|c|}
\hline Rank & Title & average & $\begin{array}{c}\text { Standard } \\
\text { deviation }\end{array}$ & $\begin{array}{c}\text { Measured } \\
\text { priority }\end{array}$ \\
\hline 1 & Quality of organization response to customers' question & 4.27 & 0.608 & 7.30 \\
\hline 2 & The good picture of organization brand & 4.07 & 0.752 & 6.75 \\
\hline 3 & price & 4.30 & 0.667 & 6.32 \\
\hline 4 & Cement delivery & 3.91 & 0.682 & 5.75 \\
\hline 5 & Offering appropriate information with products & 3.74 & 0.719 & 5.13 \\
\hline 6 & Quality of products & 3.71 & 0.861 & 5 \\
\hline 7 & Variety of products & 3.69 & 0.841 & 4.87 \\
\hline 8 & Packaging & 3.69 & 0.570 & 4.74 \\
\hline 9 & Convenience in ordering & 3.67 & 0.678 & 4.61 \\
\hline 10 & Offering incentives to encourage continuous purchase & 3.66 & 0.718 & 4.54 \\
\hline
\end{tabular}


Table 4. Ranking of the effective features in future strategic decision

\begin{tabular}{|c|l|c|}
\hline Rank & \multicolumn{1}{|c|}{ Title } & Average \\
\hline 1 & Packaging resistance against moisture & 4.29 \\
\hline 2 & Company's commitment to protect natural sources & 4.29 \\
\hline 3 & Possibility of paying by ATM & 4.18 \\
\hline 4 & Possibility of ordering by telephone and fax & 4.09 \\
\hline 5 & Existence of a 24 hour reception of customers' complaint and assurance to follow & 4.6 \\
\hline 6 & Informing the customer about cargo departure from the company & 3.96 \\
\hline 7 & Printing the necessary suggestions on the package for the efficiency of use & 3.77 \\
\hline 8 & Printing exact date and time on the package & 3.77 \\
\hline 9 & Giving advertising presents along with congratulating or condoling messages & 3.56 \\
\hline 10 & Holding periodic meeting to train the usages of cement & 3.26 \\
\hline 11 & Feasibility of internet-based ordering & 3.24 \\
\hline 12 & Feasibility of paying from internet & 3.17 \\
\hline 13 & Delivering cement in packages smaller than 50 kg & 3.07 \\
\hline 14 & Feasibility of tracing the sent cargo by the internet & 2.96 \\
\hline 15 & Taking the responsibility of transporting the cement to the destination (by the company) & 2.88 \\
\hline 16 & Delivering cement in packages bigger than 50 kg & 2.09 \\
\hline
\end{tabular}

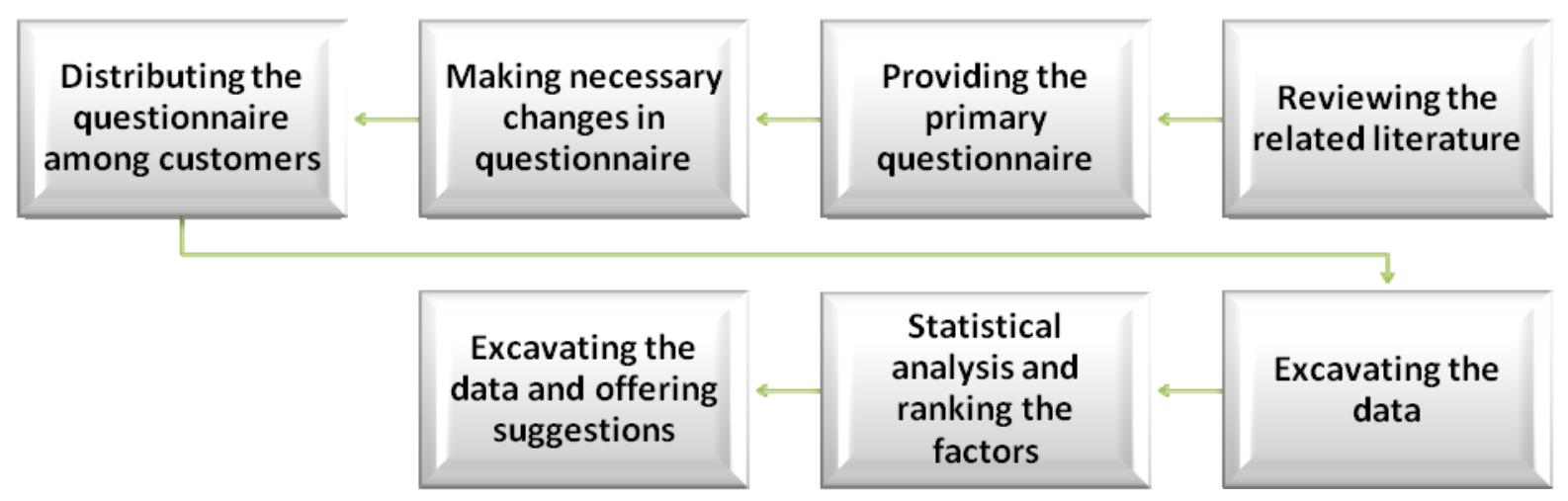

Figure 1. Stages of the research 